\title{
Risk Factors for Stunting Among Children: A Community Based Case Control Study in Nepal
}

\author{
Paudel R, Pradhan B, Wagle RR, Pahari DP, Onta SR
}

\author{
Department of Community Medicine and Public \\ Health, Institute of Medicine \\ Tribhuvan University, Nepal
}

\section{Corresponding Author}

Rajan Paudel

Department of Community Medicine and Public Health, Institute of Medicine

Tribhuvan University, Nepal

Email: paudel.rajan@gmail.com

Citation

Paudel R, Pradhan B, Wagle RR, Pahari DP, Onta SR. Risk Factors for Stunting Among Children: A Community Based Case Control Study in Nepal. Kathmandu Univ Med J 2012;39(3):18-24.

\begin{abstract}
\section{Background}

Stunting, a chronic condition, is an underlying cause of child morbidity and mortality in Nepal. This study intends to identify the factors causing stunting among children that will help to prioritize the strategies at the district level.

\section{Objective}

The objective of the study was to identify the risk factors for stunting among children of age between 6 to 59 months.
\end{abstract}

\section{Methods}

The study was based on community-based case control design in the mid-west, Surkhet Nepal from August to September 2010. The cases were stunted children and controls were the children without stunting. Data was collected by interviewing those children's mothers and measured length/height of 118 children as cases and 236 children as controls. Logistic regression analysis was performed to identify the best model of factors leading to stunting. Odds ratio and $95 \%$ confidence interval were used as a measure of association.

\section{Results}

Socio-economic risk factors for stunting comprised mothers without earning (OR=3.11, 95\% Cl 1.26-7.65), food deficit families (OR=4.26, 95\% Cl 1.73-10.45) and care taker of the children other than mother ( $O R=3.02,95 \% \mathrm{Cl} 1.19-7.70)$. Environmental risk factors for stunting consisted of kitchen without ventilation and children exposed to pesticide. Inappropriate exclusive breast feeding (OR=6.90, 95\% $\mathrm{Cl} 2.81-16.97)$, complementary feeding less than four times a day $(\mathrm{OR}=3.60,95 \% \mathrm{Cl}$ 1.32-9.95) and dietary diversity below WHO standard (OR=4.06, 95\% $\mathrm{Cl} 1.70-9.67$ ) were factors of stunted children. Diarrhea was found significantly associated with stunting (OR=7.46, 95\% Cl 2.98-18.65).

\section{Conclusions}

Stunting was found to be as a result of multiple factors such as socio-economic, environmental and inappropriate feeding practices.

\section{KEY WORDS}

Children, community, case-control study, risk factors, stunting

\section{INTRODUCTION}

Chronic malnutrition among children can be a consequence of socio-biological processes within which different factors are interrelated. A low height-for-age or stunting is a chronic condition, an underlying cause of child morbidity and mortality in Nepal, India and other developing countries. ${ }^{1-5}$. As Nepal Micronutrient Status Survey (NMSS) reported, $54 \%$ of children below five years of age were stunted in 1998. ${ }^{6}$ Although stunting is in decreasing trend over the years, prevalence of stunting is still high in Nepal. According to Nepal Demographic Health Survey (NDHS) 2001, 2006 and 2011 stunting among the children below 5 years was $50 \%, 49 \%$ and $41 \%$ respectively. This is much higher than wasting and underweight. $2,7,8$ The magnitude of stunting and severe stunting among the children in some parts of the country is even higher than the national average. For example, in Surkhet, a mid-west district of Nepal, stunting 
among less than five years children was estimated at $65.5 \%$ and severe stunting at $32.9 \% .^{9}$

The slow reduction of stunting indicates that identification of risk factors of stunting and action taken to prevent them may be an important step in Nepal. However, very few community-based studies have been conducted in Nepal with this purpose. ${ }^{10,11}$

\section{METHODS}

A community based case control study was conducted in Latikoili VDC of Surkhet district, mid-west Nepal from August to September 2010. The children of 6-59 months age and their mothers were taken as a study population by matching age and community among cases and controls. The proposal was approved by ethical review committee of Department of Community Medicine and Public Health, Institute of Medicine, Kathmandu. Verbal consent was obtained from each respondent after explaining the objectives and methods of the study. Children older than six months were included because this is the minimum age to expose to external factors and is the average age of weaning. If there were more than one eligible child in the family, the oldest one was selected. Child with physical disability was excluded from the study.

Case and control definition was ascertained by using the height-for-age indicator according to WHO new child growth standards 2006. The criterion for cases (stunting) was: Z-value less than -2 standard deviations (SDs) below the median height-for-age. Controls were children without stunting: Z-value equal to or above -2 SDs in families that had no stunted children. ${ }^{12}$

The sample size was calculated using Epi Info (3.5.1) statcalc with following values based on a study: confidence level = $95 \%$, power $(1-\beta)=80 \%$, case control ratio $=1: 1$, expected frequency of exposure in not ill $=50.7 \%$, odds ratio $=2.31$. $^{3}$ The total sample size was 212 i.e. Cases $=106$ and control= 106. Assuming $15 \%$ non response rate, 244 respondents (122 cases and 122 controls) were approached for study. Among 244 children that were approached for study, eight questionnaires were incomplete and not included in analysis. Finally, there were 236 children in the study (118 cases and 118 controls) (fig.1).

Systematic random sampling method was applied to identify the required sample size. Out of nine wards, five wards (ward no. 1, 2, 3, 8, and 9) were selected randomly. First of all, the list of households having children age 6-59 months was taken from VDC office and Health Post. Total numbers of households having children 6-59 months were 934. Then sampling interval ' $k$ ' was calculated dividing the total numbers of households (934) by required sample size (236). The first household was taken randomly and every fourth household (kth) was identified.

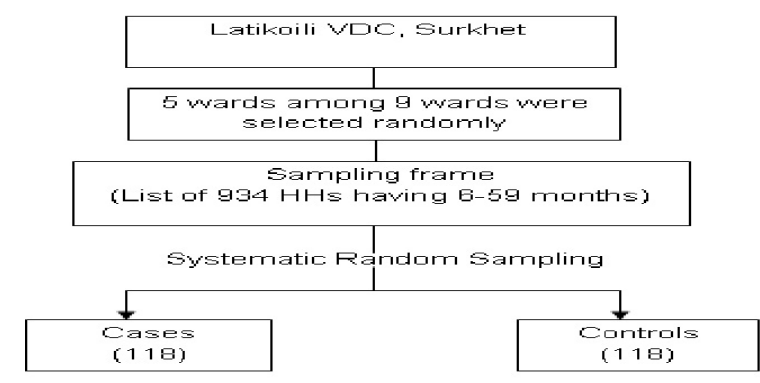

Figure 1. Sampling procedure used in the study area

Data collection technique was interview and anthropometric measurement of height or length of children. Pretesting of the tools was carried out to ensure reliability. Precision in age was maintained as it was calculated for nearest month and height of children was measured to the nearest $0.1 \mathrm{~cm}$ for the precision of the results. The preferred respondents were mothers of children between 6 to 59 months. Data was collected by direct involvement of researcher through house to house visit. The height was measured by using a measuring tape for children aged 25-59 months while the length was measured by using a portable calibrated board for children aged 6-24 months.

First the subject was assessed for stunting. The interviewer measured and recorded the length/height of each child aged between 6 to 59 months. Mother of stunted children was interviewed as cases and mother of children without stunting was interviewed as controls about the past exposure. The same questionnaire for cases and controls was used to collect data.

Analysis was carried out at two levels. Firstly, a bivariate analysis was performed to determine the differentials of under-five stunting by explanatory variables. Chi-square test was performed to test the existence of significant association between stunting and selected risk factors. Secondly, the significant variables ( $p$-value < 0.05) observed in bivariate analysis were included in multivariate analysis. Logistic regression model was applied to examine independent associations between explanatory variables and a binary dependent variable (stunting). The statistical analysis was carried out using SPSS 17.0. Hosmer and Lemeshow chi-square test was applied to test the logistic regression model for goodness of fit.

\section{RESULTS}

Higher proportion (41.5\%) of children under study was in the age group 19-36 months followed by the age group 3759 and 6-18 months. Age group of cases and controls were more or less similar. Mean age of cases and controls were $29.4 \pm 15.5$ and $30.3 \pm 15.2$ months respectively. The cases were $56.8 \%$ male and $43.2 \%$ female for the study.

More than one fifths of mothers (21.6\%) were illiterate. Illiterate mothers were higher among cases than in controls. 
Majority of mothers, $53.4 \%$ of the cases and $38.1 \%$ of controls were housewife and about one fifth (20.3\%) were engaged in small business. The percentage of mothers who were involved in agriculture and service was similar; $11.9 \%$ each, which is followed by daily labour (10.2\%). Janjatis were high (41.5\%) that included about $38 \%$ Tharus in study area. Second largest group of ethnicity was upper caste (Brahmin/Chhetri) (33.1\%) which was followed by Dalit (25.4\%). Proportion of Dalit was higher among cases than in controls.

Families with poor economic status were higher among cases $(62.7 \%)$ than controls $(39.8 \%)$. Most of the families $(65.3 \%)$ with cases had no food security compared with the families (35.6\%) having controls (table 1).

Table 1. Socio-demographic and economic characteristics of the study population.

\begin{tabular}{|c|c|c|c|}
\hline Characteristics & $\begin{array}{l}\text { Cases (\%) } \\
\mathrm{n}=118\end{array}$ & $\begin{array}{l}\text { Controls }(\%) \\
n=118\end{array}$ & $\begin{array}{l}\text { Total (\%) } \\
n=236\end{array}$ \\
\hline \multicolumn{4}{|c|}{ Age of children (months) } \\
\hline $6-18$ & $31(26.3)$ & $29(24.6)$ & $60(25.4)$ \\
\hline $19-36$ & 49 (41.5) & 49 (41.5) & $98(41.5)$ \\
\hline $37-59$ & $38(32.2)$ & 40 (33.9) & $78(33.1)$ \\
\hline $\begin{array}{l}\text { Mean age of children } \\
\text { (months) }\end{array}$ & $29.4 \pm 15.5$ & $30.3 \pm 15.2$ & $29.8 \pm 15.3$ \\
\hline \multicolumn{4}{|l|}{ Sex of children } \\
\hline Male & $67(56.8)$ & $64(54.2)$ & $131(55.5)$ \\
\hline Female & $51(43.2)$ & $54(45.8)$ & 105 (44.5) \\
\hline \multicolumn{4}{|l|}{ Education of mother } \\
\hline Illiterate & $38(32.2)$ & $13(11.0)$ & $51(21.6)$ \\
\hline Non-formal education & $28(23.7)$ & 15 (12.7) & $43(18.2)$ \\
\hline Primary & $19(16.1)$ & $32(27.1)$ & $51(21.6)$ \\
\hline Secondary & $17(14.4)$ & 27 (22.9) & $44(18.6)$ \\
\hline SLC or above & $16(13.6)$ & $31(26.3)$ & $47(19.9)$ \\
\hline \multicolumn{4}{|l|}{ Occupation of mother } \\
\hline House wife & $63(53.4)$ & $45(38.1)$ & $108(45.8)$ \\
\hline Agriculture & $13(11.0)$ & $15(12.7)$ & 28 (11.9) \\
\hline Small business & $18(15.3)$ & $30(25.4)$ & $48(20.3)$ \\
\hline Daily labour & $12(10.2)$ & $12(10.2)$ & $24(10.2)$ \\
\hline Service & $12(10.2)$ & $16(13.6)$ & $28(11.9)$ \\
\hline \multicolumn{4}{|l|}{ Ethnicity } \\
\hline Upper caste & 40 (33.9) & $38(32.2)$ & $78(33.1)$ \\
\hline Janjatis & $46(39.0)$ & $52(44.1)$ & $98(41.5)$ \\
\hline Dalit & $32(27.1)$ & $28(23.7)$ & $60(25.4)$ \\
\hline \multicolumn{4}{|c|}{ Economic status of family } \\
\hline Poor & $74(62.7)$ & $47(39.8)$ & $121(51.3)$ \\
\hline Medium & 20 (16.9) & $11(09.3)$ & 31 (13.1) \\
\hline Rich & $24(20.3)$ & $60(50.8)$ & $84(35.6)$ \\
\hline \multicolumn{4}{|l|}{ Food security of family } \\
\hline Yes & $41(34.7)$ & $76(64.4)$ & $117(49.6)$ \\
\hline No & $77(65.3)$ & $42(35.6)$ & $119(50.4)$ \\
\hline
\end{tabular}

Bivariate analysis revealed strong association of stunting with feeding practices of children like exclusive breast feeding, food diversity and complementary feeding of the children. Childhood diseases like Acute Respiratory Infection and diarrhea were also found associated with childhood stunting. Among the socio-economic indicators, risk of stunting was five times higher among the children whose mothers did not have any earning compared to those who had earning. In bivariate analysis, low birth weight of the child, illiteracy of mothers, food securities in the family were found as risk factor for stunting (table 2).

Table 3 presents the final explanatory model of stunting Table 3. Factors associated with stunting, multivariate analysis.

\begin{tabular}{|c|c|c|c|c|}
\hline Variables & $\begin{array}{l}\text { Beta Coef- } \\
\text { ficient }\end{array}$ & $\begin{array}{l}\text { Standard } \\
\text { Error }\end{array}$ & $\begin{array}{l}\text { Unadjusted } \\
\mathrm{OR}(\mathrm{Cl} \text { at } 95 \%)\end{array}$ & $\begin{array}{l}\text { Adjusted OR } \\
(\mathrm{Cl} \text { at } 95 \%)\end{array}$ \\
\hline \multicolumn{5}{|c|}{ No earning of mother } \\
\hline Yes & 1.13 & 0.46 & $\begin{array}{l}5.31(3.03- \\
9.29)\end{array}$ & $\begin{array}{l}3.11(1.26- \\
7.65)\end{array}$ \\
\hline No & & & & 1 \\
\hline \multicolumn{5}{|c|}{ No food security of family } \\
\hline Yes & 1.45 & 0.46 & $\begin{array}{l}3.40 \text { (1.99- } \\
5.80)\end{array}$ & $\begin{array}{l}4.26(1.73- \\
10.45)\end{array}$ \\
\hline No & & & & 1 \\
\hline \multicolumn{5}{|l|}{ Care giver } \\
\hline Others & 1.11 & 0.48 & $\begin{array}{l}3.44 \text { (1.99- } \\
5.95)\end{array}$ & $\begin{array}{l}3.02 \text { (1.19- } \\
7.70)\end{array}$ \\
\hline Mother & & & & 1 \\
\hline \multicolumn{5}{|c|}{ No ventilation of kitchen } \\
\hline Yes & 1.35 & 0.45 & $\begin{array}{l}3.41 \text { (1.99- } \\
5.84)\end{array}$ & $\begin{array}{l}3.85 \text { (1.59- } \\
9.35)\end{array}$ \\
\hline No & & & & 1 \\
\hline \multicolumn{5}{|c|}{ Pesticide exposure } \\
\hline Yes & 1.25 & 0.49 & $\begin{array}{l}3.26(1.86- \\
5.71)\end{array}$ & $\begin{array}{l}3.51(1.33- \\
9.23)\end{array}$ \\
\hline No & & & & 1 \\
\hline \multicolumn{5}{|c|}{ Exclusive breast feeding } \\
\hline $\begin{array}{l}<\text { or }>6 \\
\text { months }\end{array}$ & 1.93 & 0.46 & $\begin{array}{l}6.96(3.92- \\
12.33)\end{array}$ & $\begin{array}{l}6.90(2.81- \\
16.97)\end{array}$ \\
\hline $\begin{array}{l}\text { Up to } 6 \\
\text { months }\end{array}$ & & & & 1 \\
\hline \multicolumn{5}{|c|}{ Feeding times } \\
\hline $\begin{array}{l}\text { Less than } 4 \\
\text { times }\end{array}$ & 1.29 & 0.51 & $\begin{array}{l}3.48 \text { (1.90- } \\
6.37)\end{array}$ & $\begin{array}{l}3.60(1.32- \\
9.95)\end{array}$ \\
\hline $\begin{array}{l}4 \text { times or } \\
\text { more }\end{array}$ & & & & 1 \\
\hline \multicolumn{5}{|c|}{ Food diversity } \\
\hline $\begin{array}{l}\text { Below } \\
\text { standard }\end{array}$ & 1.40 & 0.44 & $\begin{array}{l}7.28 \text { (4.09- } \\
12.94)\end{array}$ & $\begin{array}{l}4.06(1.70- \\
9.67)\end{array}$ \\
\hline Standard & & & & 1 \\
\hline \multicolumn{5}{|l|}{ Diarrhoea } \\
\hline $\begin{array}{l}\text { One or } \\
\text { more times }\end{array}$ & 2.01 & 0.47 & $\begin{array}{l}4.18(2.42- \\
7.22)\end{array}$ & $\begin{array}{l}7.46(2.98- \\
18.65)\end{array}$ \\
\hline No illness & & & & 1 \\
\hline Constant & -6.63 & 0.89 & & \\
\hline
\end{tabular}


Table 2. Factors associate with stunting; bivariate analysis.

\begin{tabular}{|c|c|c|c|c|}
\hline Characteristics & $\begin{array}{l}\text { Cases } \\
n=118\end{array}$ & $\begin{array}{l}\text { Controls } \\
n=118\end{array}$ & $\begin{array}{l}\text { Total (\%) } \\
n=236\end{array}$ & $\begin{array}{l}\text { Unadjusted OR } \\
(95 \% \text { C I) }\end{array}$ \\
\hline \multicolumn{5}{|l|}{ Education of mother } \\
\hline Illiterate & 38 & 13 & $51(21.6)$ & $3.84(1.92-7.68)$ \\
\hline Literate & 80 & 105 & $185(78.4)$ & 1 \\
\hline \multicolumn{5}{|c|}{ Occupation of mother } \\
\hline House wife & 83 & 45 & $108(45.8)$ & $1.86(1.11-3.12)$ \\
\hline Others & 55 & 73 & $128(54.2)$ & 1 \\
\hline \multicolumn{5}{|c|}{ Economic status of family } \\
\hline Poor & 74 & 47 & $121(51.3)$ & $2.54(1.50-4.30)$ \\
\hline Medium or rich & 44 & 71 & $115(48.7)$ & 1 \\
\hline \multicolumn{5}{|c|}{ No earning of mother } \\
\hline Yes & 88 & 42 & $130(55.1)$ & $5.31(3.03-9.29)$ \\
\hline No & 30 & 76 & 106 (44.9) & 1 \\
\hline \multicolumn{5}{|c|}{ No food security of family } \\
\hline Yes & 77 & 42 & $119(50.4)$ & $3.40(1.99-5.80)$ \\
\hline No & 41 & 76 & $117(49.6)$ & 1 \\
\hline \multicolumn{5}{|c|}{ Age of mother (at child birth) } \\
\hline$<20$ and $>35$ years & 77 & 48 & $125(53.0)$ & $2.74(1.62-4.64)$ \\
\hline $20-35$ years & 41 & 70 & $111(47.0)$ & 1 \\
\hline \multicolumn{5}{|l|}{ Care giver } \\
\hline Others & 65 & 31 & $96(40.7)$ & $3.44(1.99-5.95)$ \\
\hline Mother & 53 & 87 & $140(59.3)$ & 1 \\
\hline \multicolumn{5}{|l|}{ Antenatal visits } \\
\hline Less than 4 visits & 71 & 48 & $119(50.4)$ & $2.20(1.31-3.70)$ \\
\hline Four or more visits & 47 & 70 & $117(49.6)$ & 1 \\
\hline \multicolumn{5}{|c|}{ No purification of water } \\
\hline Yes & 82 & 65 & $147(62.3)$ & $1.86(1.09-3.17)$ \\
\hline No & 36 & 53 & $89(37.7)$ & 1 \\
\hline \multicolumn{5}{|l|}{ Type of cooking fuel } \\
\hline Solid & 106 & 94 & $200(84.7)$ & $2.25(1.07-4.76)$ \\
\hline Gas or bio gas & 12 & 24 & $36(15.3)$ & 1 \\
\hline \multicolumn{5}{|c|}{ Type of cooking stove } \\
\hline Not improved & 66 & 43 & $109(46.2)$ & $2.21(1.31-3.73)$ \\
\hline Improved & 52 & 75 & $127(53.8)$ & 1 \\
\hline \multicolumn{5}{|c|}{ No ventilation of kitchen } \\
\hline Yes & 80 & 45 & $125(53.0)$ & $3.41(1.99-5.84)$ \\
\hline No & 38 & 73 & $111(47.0)$ & 1 \\
\hline \multicolumn{5}{|c|}{ Exposure of pesticide } \\
\hline Yes & 58 & 27 & $85(36.0)$ & $3.26(1.86-5.71)$ \\
\hline No & 60 & 91 & $151(64.0)$ & 1 \\
\hline \multicolumn{5}{|c|}{ No colostrums feeding } \\
\hline Yes & 77 & 42 & 119 (50.4) & $3.40(1.99-5.80)$ \\
\hline No & 41 & 76 & $117(49.6)$ & 1 \\
\hline \multicolumn{5}{|c|}{ Exclusive breast feeding } \\
\hline$<6$ or $>6$ months & 88 & 35 & $123(52.1)$ & $6.96(3.92-12.33)$ \\
\hline Up to 6 months & 30 & 83 & 113 (47.9) & 1 \\
\hline \multicolumn{5}{|c|}{ Complementary feeding } \\
\hline $\begin{array}{l}\text { Before or after } 6 \\
\text { months }\end{array}$ & 88 & 35 & $123(52.1)$ & $6.96(3.92-12.33)$ \\
\hline
\end{tabular}




\begin{tabular}{|c|c|c|c|c|}
\hline Characteristics & $\begin{array}{l}\text { Cases } \\
n=118\end{array}$ & $\begin{array}{l}\text { Controls } \\
n=118\end{array}$ & $\begin{array}{l}\text { Total (\%) } \\
n=236\end{array}$ & $\begin{array}{l}\text { Unadjusted OR } \\
(95 \% \text { C I) }\end{array}$ \\
\hline During 6 months & 30 & 83 & 113 (47.9) & 1 \\
\hline \multicolumn{5}{|c|}{ Feeding times (in a day) } \\
\hline Less than 4 times & 98 & 69 & $167(70.8)$ & $3.48(1.90-6.37)$ \\
\hline Four times or more & 20 & 49 & $69(29.2)$ & \\
\hline \multicolumn{5}{|c|}{ Minimum food diversity } \\
\hline Below standard & 89 & 35 & $124(52.5)$ & $7.28(4.09-12.94)$ \\
\hline Standard & 29 & 83 & $112(47.5)$ & 1 \\
\hline \multicolumn{5}{|l|}{ Birth weight of child } \\
\hline Small & 84 & 42 & $126(53.4)$ & $4.47(2.58-7.74)$ \\
\hline Normal & 34 & 76 & $110(46.6)$ & 1 \\
\hline \multicolumn{5}{|l|}{ ARI } \\
\hline One time or more & 89 & 47 & $136(57.6)$ & $4.64(2.65-8.10)$ \\
\hline No illness & 29 & 71 & $100(42.4)$ & 1 \\
\hline \multicolumn{5}{|l|}{ Diarrhoea } \\
\hline One time or more & 85 & 45 & $130(51.4)$ & $4.18(2.42-7.22)$ \\
\hline No illness & 33 & 73 & 106 (44.9) & 1 \\
\hline
\end{tabular}

based on multivariate analysis. Strong association was observed between exclusive breast feeding, minimum food diversity, diarrhea and stunting. Inappropriate exclusive breast feeding was higher among the cases than in controls (OR=6.90,95\% Cl 2.81-16.97). The odds of getting stunting was 7.46 times higher among the children who had diarrhea one or more times in past two months than those who did not have (OR=7.46, 95\% Cl 2.98-18.65).

Mothers having no earning was higher among stunted children as compared to not stunted (OR=3.11, 95\% Cl 1.26-7.65). The odds of getting stunting was 4.26 times higher among food insecure families than in food secure families (OR=4.26, 95\% Cl 1.73-10.45). The care-taker of children other than mother was found risk factor for stunting (OR=3.02, 95\% Cl 1.19-7.70). No ventilation in kitchen was significantly higher among cases as compared to controls (OR=3.85, 95\% Cl 1.59-9.35). It was also found that exposure of pesticide to the children was statistically significant with stunting (OR=3.51, Cl 1.33-9.23). Complementary feeding of the children less than 4 times a day was higher among the cases than controls (OR=3.60, 95\% $\mathrm{Cl} 1.32-9.95)$. Minimum dietary diversity below the standard of WHO was also a risk factor for stunting among the children (OR=4.06, 95\% $\mathrm{Cl} 1.70-9.67)$.

\section{DISCUSSION}

Although this study did not show any significant association of stunting with sex of child, few studies conducted in Ethiopia and Nepal showed significant relationship between stunting and sex of children.,13 The illiteracy was 3.84 times higher among the mothers of cases than those of controls (OR=3.84 95\% Cl 1.92-7.68). NDHS and a cross-sectional study in eastern Terai, Nepal has shown the percentage of children stunted decreases as mother's education level increases. ${ }^{8,10}$

Earning of mother was associated with stunting status of children (OR=3.11, 95\% Cl 1.26-7.65). Demographic and Health Surveys of 11 out of 36 focus countries showed that in most countries the poor children have about twice as much stunting as the wealthier children. ${ }^{14} \mathrm{NDHS}$ has also shown that children in the highest wealth quintile are least likely to be stunted. ${ }^{8}$ A study showed that the standard of living scores were strongly related to underweight and stunting in both the bivariate and the multiple regression analyses. ${ }^{10}$ These results suggest that low income has undesirable outcome.

Food security was an important risk factor for stunting and statistically significant in subsequent multivariate analysis. The families with no food security were 4.26 times higher in the cases than in controls. Similarly, more food insecure households had low monthly income, no electricity or toilet facility and less household durable assets. ${ }^{15}$ It was found that food security was associated with earning status of mother and economic status of family, that eventually associated with stunting status of children. The child being cared for most of the time by other family members was at 3 fold higher risk for stunting as compared to care provided by mothers. A case control study conducted in Mexico has shown that the care exclusively provided by mother had a protective effect for stunting. ${ }^{5}$

Effect of post-natal care, place of delivery, delivery assisted by health worker and immunization in children was not as much high as that of other studies. ${ }^{4,16}$ Health service utilization can make a difference in the nutritional status of children, it might be due to that mothers are aware of importance of good nutrition and increasing frequency of the health seeking behavior during illness.

Most of the respondents (84.7\%) used solid fuel for cooking and about $46 \%$ respondents had no improved cooking 
stove. Effect for these factors found in bivariate analysis disappeared in multivariate analysis. Having no ventilation of kitchen was found independent risk factor of stunting (OR=3.85, 95\% Cl 1.59-9.35). A study showed that indoor air pollution reduces the $\mathrm{O}_{2}$ delivery to placenta and fetal uptake that result the low birth weight and length. ${ }^{17}$ By this result it can be concluded that no ventilation in the kitchen is independent to cause stunting even the fuel is gas or biogas and stove is improved. But this result should be cautiously interpreted because the study hasn't identified the level of exposure of children to indoor air pollution. About $14 \%$ respondents did not use toilet and practicing open defecation but it was not associated with stunting. However a study in Uganda showed the relationship between latrine use and stunting. The household with no latrine had more likely stunted children than those who had. ${ }^{18}$

An interesting finding in this study was the relationship between exposure to pesticides and children's stunting status. About $65 \%$ of respondents used pesticides in their vegetable garden or cultivated land and $36 \%$ of mother and children were exposed to pesticides. The exposure of pesticides was 3.51 times higher among stunted children as compared to not stunted (OR=3.51, $\mathrm{Cl} 1.33-9.23)$. A study conducted in Andes showed that deficits in protein, thiamin and riboflavin intake were more prevalent in communities with more intensive use of pesticides than those with less. Across all intensities, frequent use of highly hazardous pesticides was associated with adverse health effects and nutritional status of people. ${ }^{19}$

This study further explored that inappropriate infant and young child feeding practices were the key factors for child stunting. Inappropriate exclusive breast feeding was 6.9 times higher among the cases than in controls (OR=6.90, $95 \% \mathrm{Cl} 2.81-16.97)$. Studies conducted in Libiya and Nepal showed infants who were exclusively breast-fed either less than six months or more than eight months were more likely to be underweight and stunting. Longer breast feeding was associated with both moderate and severe stunting. ${ }^{4,10}$ It has been found that complementary feeding to the children less than 4 times a day was 3.6 times higher among the cases than in controls. Similarly, dietary diversity below WHO standard was significantly higher among the stunting children even after controlling for other important variables in the multivariate regression analysis ( $O R=4.06$, $95 \% \mathrm{Cl} 1.70-9.67)$. A case control study in Vietnam showed that after adjusting for other factors in the model, children whose mothers inappropriately provided food to them had a 1.9 times greater risk of getting stunted than those whose mothers fed them appropriately. ${ }^{20}$ These findings suggest that child feeding practices can make a difference in stunting status of children.

This study showed that more than half of children (53.4\%) were small or low weight at birth, among them $66.6 \%$ were stunted. Low birth weight or 'small at birth' were 4.47 times more in stunted children than those of not stunted.
But in subsequent multivariate analysis the association was not seen. Studies conducted in Libiya, Vietnam and Nepal found a relationship between birth weight and nutritional status of children. Children who were low weight at birth or 'small at birth' were significantly more likely to be stunted than normal weight and 'size' at birth. ${ }^{4,10,20}$

This study found that ARI was not significantly associated with stunting while adjusting the possible risk factors but getting diarrhea one or more times in past two months was 7.46 times higher among cases as compared to controls after adjusting confounding variables (OR=7.46, 95\% Cl 2.98-18.65). There may be the question of temporality for ARI and diarrhea, but the surrounding environment and social context where child grows up were the factors for ARI and diarrhoea among children. It was ensured during the study that those factors were embodied since many years in these settings resulting recurrent diarrhoea. Studies done in Libiya and Ethiopia have also showed that incidence of diarrhea was positively and significantly associated with stunting. ${ }^{3,4}$ This might be due to reduced appetite, less quantity of fluids and foods given during diarrhea and other sickness. ${ }^{13}$

The limitation of the study is that whether wasting and underweight were among the controls was not clarified. It is a relatively long period to expect people to remember details of initiation of breast feeding and whether or not colostrums feeding, but the recall problem hopefully was of nondifferential nature. Exposure of pesticide and indoor air pollution was only based on the verbal expression, the level of concentration of exposure was not measured.

\section{CONCLUSION}

Socio-economic risk factors for stunting comprised mothers without earning, food deficit families and care taker of the children other than mother. Environmental risk factors for stunting consisted of kitchen without ventilation and children exposed to pesticide. Inappropriate feeding practices were identified as major risk factor for stunting. Childhood disease such as diarrhea was found significantly associated with stunting. All these factors should be taken into consideration to address stunting in the community. This study suggests that the role of the mother is important as primary caregiver for young children to ensure nutrition and prevent from environmental hazards and childhood diseases.

\section{ACKNOWLEDGEMENTS}

We would like to extend our cordial thanks to Department of Community Medicine and Public Health, Institute of Medicine (IoM), Mother and Infant Research Activities (MIRA), Peoples' Health Initiative (PHI), District Public Health Office (DPHO), Surkhet and research participants for their cooperation and support. 


\section{REFERENCES}

1. Mishra VK, Lahiri S, Luther NY. Child Nutrition in India: National Family Health Survey Subject Reports. International Institute for Population Sciences Mumbai, India/ East-West Center. Population and Health Studies Honolulu, Hawaii, USA; 1999 June.

2. Ministry of Health Nepal, New ERA, and ORC Macro. Nepal Demographic and Health Survey (NDHS);2011.

3. Teshome B, Makau WK, Getahun Z, Taye G. Magnitude and determinants of stunting in children under five years of age in food surplus region of Ethiopia: The case of West Gojam Zone. Ethiop J Health Dev 2009; 23(2):98-106.

4. Taguri AEI, Betilmal I, Mahmud SM, Ahmed AM, Goulet O, Galan P et al. Risk factors for stunting among under-five in Libiya. Public Health Nutr 2008;12(8):1141-1149.

5. Reyes H, Perez-C R, Sandoval A, Castillo R, Santos JI, Doubova SV et al. The family as a determinant of stunting in children living in conditions of extreme poverty: a case control study. BMC Public Health [Internet]. 2004 Nov [cited 2010 Sept 14];4(57):Available from: http://www. biomedcentral.com/1471-2458/4/57.

6. Ministry of Health Nepal, New ERA, Micronutrient Initiative, UNICEF Nepal and WHO. Nepal Micronutrient Status Survey (NMSS);1998.

7. Ministry of Health Nepal, New ERA, and ORC Macro. Nepal Demographic and Health Survey (NDHS) 2001;185-190.

8. Ministry of Health and Population Nepal, New ERA, and Macro International Inc. Nepal Demographic and Health Survey (NDHS) 2006;192-195.

9. WHO/OCHA/Nepal Government. Nepal District Health Profile: Baseline Data Through Secondary sources. EHA Publication no. 22, Kathmandu;2007 Dec.

10. Sing GCP, Nair M, Grubesic RB. Factors associated with underweight and stunting among children in Rural Terai of Eastern Nepal. Asia Pac J Public Health 2009;21(2):143-152.
11. Sah N. Determinants of child malnutrition in Nepal: a case analysis from Dhanusha, central Terai of Nepal. 2005 [cited 2010 October 2] Available from: http://iussp2005.princeton.edu/download. aspx?submissionld=51628.

12. World Health Organization. WHO child growth standard 2006 field tables. [cited 2010 June 14] Available from: http://www.who.int/ childgrowth/standards/height_for_age_field/en/index.html

13. National Planning Commission Secretariat Nepal and UNICEF Nepal. Nepal Multiple Indicator Surveillance (NMIS): Early Childhood Feeding, Nutrition and Development, Fourth Cycle; 1996.

14. Black RE, Allen LH, Bhutta ZA, Caulfield LE, Onis MD, Ezzati M et al. For the Maternal and Child Undernutrition Group. Maternal and child undernutrition: global and regional exposures and health consequences. Lancet 2008 January

15. Helen Keller International (HKI) Nepal. Household food insecurity and nutritional status of children aged 6-23 months in Kailali district of Nepal. Nepal Nutrition and Food security Bulletin; 2010.

16. Bloss E, Wainaina F, Bailey RC. Prevalence and predictors of underweight, stunting, and wasting among children aged 5 and under in western Kenya. J Trop Pediatr 2004; 50:260-270.

17. Smith KR, Samet J M, Romieu I, Bruce N. Indoor air pollution in developing countries and acute lower respiratory infections in children. Thorax 2000; 55:518-532.

18. Wamani H, Astrøm AN, Peterson S. Predictors of poor anthropometric status among children under 2 years of age in rural Uganda. Public Health Nutr 2006;9(3):320-326.

19. Orozco F, Cole DC, Muñoz V, Muñoz V, Altamirano A, Wanigaratne $S$ et al. Relationships among production systems, preschool nutritional status, and pesticide-related toxicity in seven Ecuadorian communities: A multi-case study approach. The United Nations University Food and Nutrition Bulletin 2007;28: 2.

20. Anh VTN, Chompikul J, and Isaranurug S. Relationship between stunting and food provided to children aged from 6 to 24 months in Soc Son District, Hanoi. J Public Health and Dev 2009;7(3):43-58. 